\title{
A novel 3D-printed locking cage for anterior atlantoaxial fixation and fusion: case report and in vitro biomechanical evaluation
}

Shenglin Wang, Huijie Leng, Yinglun Tian, Nanfang Xu and Zhongjun Liu*

\begin{abstract}
Background: Treatment of atlantoaxial dislocation is aimed at reduction and stabilization of the atlantoaxial joint. $3 \mathrm{D}$ printing refers to a process where additive manufacturing is achieved under precise computer control. Literature on its utilization in anterior atlantoaxial fixation and fusion is rare. This study is the first report on a 3D-printed locking cage used in the anterior procedure for atlantoaxial dislocation.

Methods: A middle-aged male in his 40s presented with weakness and numbness of his extremities for 3 years and could only walk slowly with assistance. Imaging studies revealed severe anterior migration of C1, irreducible atlantoaxial dislocation, and severe cervical-medullary compression. A preoperative plan consisting of trans-oral soft tissue release and fixation using tailor-designed 3D-printed cages was devised. Following fluoroscopic confirmation of reduction of the atlantoaxial joints, two customized 3D-printed cages made of titanium alloy were inserted into the bilateral facet joints, which were then locked by six screws into the lateral masses of C1 and C2. The microstructure of the inserted cages was optimized for improved biomechanical stability and enhanced osseointegration, without the need for bone grafting. In addition, a biomechanical test was performed on seven human cadaveric specimens comparing the novel implant with the conventional C1 lateral mass-C2 pedicle screw construct in three modes of motion (flexion-extension, lateral bending, axial rotation).
\end{abstract}

Results: Improvement of neurologic function in the patient was evident immediately after surgery. He was able to walk independently 1 month post-operatively. At the 12-month follow-up, coronal reconstruction of CT demonstrated properly-positioned 3D-printed cages, evidence of osseo-integration at the bone-implant interface, and no subsidence or displacement of the implant. Eighteen months out of surgery, the mJOA score improved to 15, and lateral X-ray confirmed reduction of atlanto-axial dislocation. Additionally, the new construct provided strong fixation comparable to that conferred by conventional constructs as there was no significant difference observed between the two groups in all three directions of motion.

Conclusions: The novel implant represents a new option in the treatment of irreducible atlantoaxial dislocation. It can provide strong anterior support for solid fixation and fusion with a low profile and a microstructure that obviates the need for bone grafting.

Keywords: Irreducible atlantoaxial dislocation, 3D-printed implant, Patient-specific implants, Range of motion

\footnotetext{
* Correspondence: puthliuzhongjun@163.com

Department of Orthopaedics, Peking University Third Hospital, Beijing,

People's Republic of China

(c) The Author(s). 2021 Open Access This article is licensed under a Creative Commons Attribution 4.0 International License, which permits use, sharing, adaptation, distribution and reproduction in any medium or format, as long as you give appropriate credit to the original author(s) and the source, provide a link to the Creative Commons licence, and indicate if changes were made. The images or other third party material in this article are included in the article's Creative Commons licence, unless indicated otherwise in a credit line to the material. If material is not included in the article's Creative Commons licence and your intended use is not permitted by statutory regulation or exceeds the permitted use, you will need to obtain permission directly from the copyright holder. To view a copy of this licence, visit http://creativecommons.org/licenses/by/4.0/. The Creative Commons Public Domain Dedication waiver (http://creativecommons.org/publicdomain/zero/1.0/) applies to the data made available in this article, unless otherwise stated in a credit line to the data.
} 


\section{Background}

In the management of irreducible atlantoaxial dislocation (IAAD), the goal of treatment consists of restoration of the normal anatomy of the cranio-vertebral junction (CVJ), complete decompression of the lower medulla and the upper spinal cord, and stabilization of the atlantoaxial joints $[1,2]$. The main procedures reported in the literature include trans-oral odontoidectomy or peri-odontoid tissue release followed by posterior occipito-cervical or atlanto-axial fusion [3-5]. Anterioronly (with peri-odontoid soft tissue release followed by anterior fixation) represents another strategy which eliminates the need for a two-step operation [6]. This single-stage procedure used a reduction plate to achieve decompression, reduction and fusion, all through a transoral incision. However, the trans-oral reduction plate had a high profile and still required bone harvest from the iliac crest [6], as did the two-stage procedures. Although there had been attempts on using rapid prototyping (3D printing) to facilitate instrumentation in the upper cervical spine $[7,8]$, to our knowledge, its utilization in anterior atlantoaxial fixation has not been reported. We herein describe the use of a novel self-locking implant with semi-constrained screws in a patient with IAAD. In addition, the biomechanics of this new 3D-printed locking cage (3DPLC) was evaluated in seven cadaver specimens.

\section{Methods}

\section{Clinical report}

A 44-year-old man presented with weakness and numbness of both upper and lower extremities for 3 years and had no history of cervical trauma. He could ambulate using a walker and had deficits of motor function in the right hand. His mJOA (modified Japanese Orthopaedic Association, supplementary file) [9] score was 11. Sensory dysfunction of the upper extremities was detected upon neurological examination and symmetric hyperreflexia was present in the lower extremities. Positive Hoffmann's signs were elicited bilaterally. His gait was wide-based, spastic, and unsteady. The patient also had limited cervical flexion and extension. Imaging studies revealed AAD with severe anterior translation of $\mathrm{C} 1$ on $\mathrm{X}$-ray (Fig. 1a) and significant cervical-medullary cord

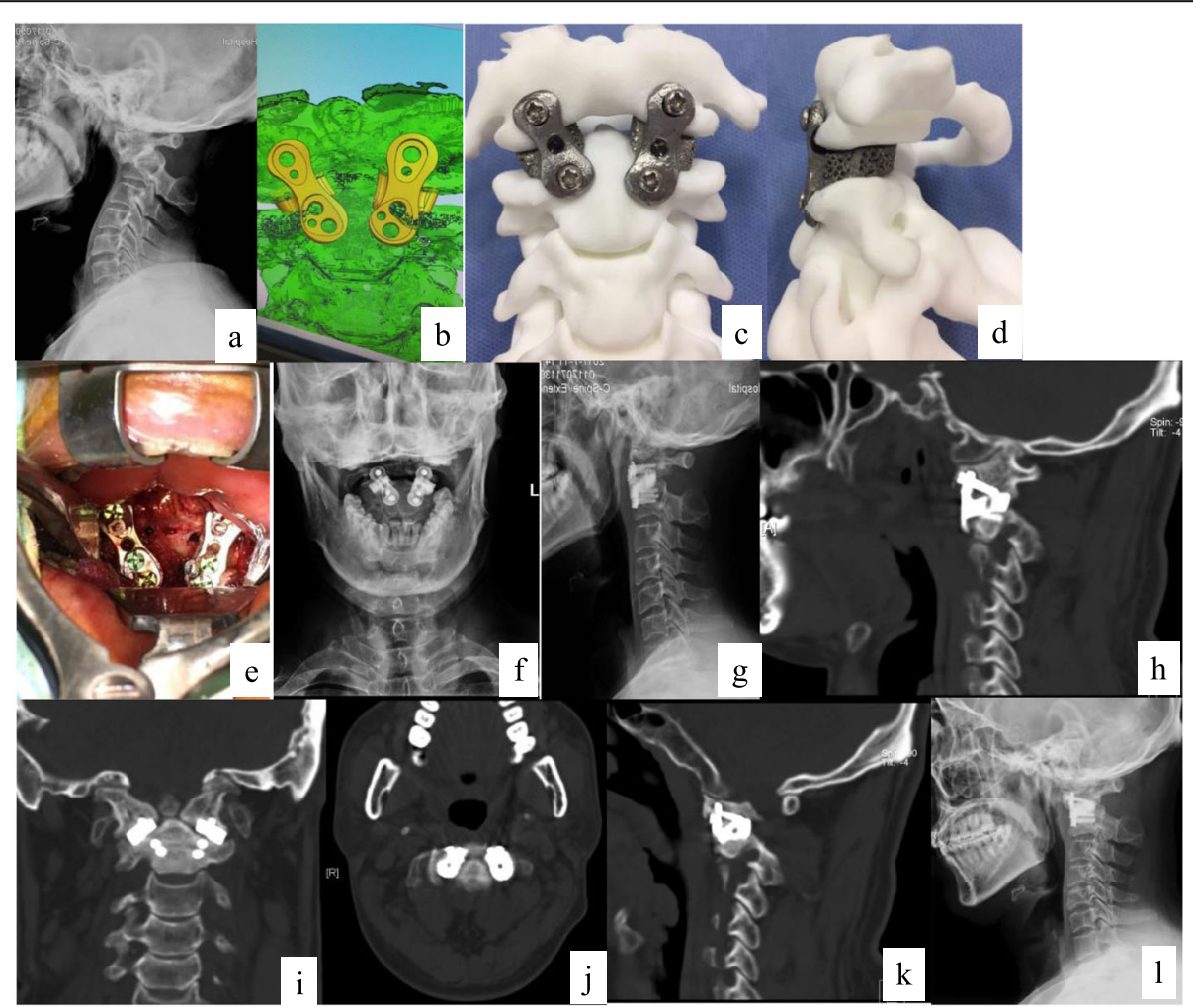

Fig. 1 a Pre-operatively lateral X-ray; $\mathbf{b}$ Anterior view of the computer-aided design model of 3DPLC; c Anterior view of the manufactured 3DPLC based on 1b on a 3D-printed model; d Lateral view of the manufactured 3DPLC based on 1b on a 3D-printed model; e Intra-operative view of the 2 3DPLC before closure; $\mathbf{f}$ Anteroposterior $\mathbf{X}$-ray 1 week after the surgery; $\mathbf{g}$ Lateral X-ray 1 week after the surgery; $\mathbf{h}$ Left sagittal reconstruction of $C T$ of the cervical spine 12 months post-operatively; $\mathbf{i}$ Coronal reconstruction of $C T$ of the cervical spine 12 months postoperatively; j Axial CT of the cervical spine 12 months post-operatively; k Right sagittal reconstruction of CT of the cervical spine 12 months postoperatively; I Lateral X-ray 18 months after the surgery 
compression with high signal intensity on T2 MRI. He was diagnosed of IAAD, and as it was not reduced with a 1/5 body weight cranial traction, trans-oral peri-odontoid release was required to allow for anatomic reduction [5]. Additionally, in order to obviate an additional posterior procedure to provide fixation and fusion, with informed consent from the patient, we decided to use a novel implant, the 3DPLC, to perform an anterior-only surgery. The 3DPLC was manufactured using titanium alloy powder based on a pre-designed computer model customized to the specific anatomy of the $\mathrm{C} 1-\mathrm{C} 2$ facet joint of this particular patient (Fig. 1b,c, d, and e). The model was built from a thin-cut CT scan of the upper cervical spine using Materialise Interactive Medical Image Control System (MIMICS). During the procedure, complete reduction was first achieved following peri-odontoid soft tissue release, and the two tailor-fabricated 3DPLCs were implanted into the $\mathrm{C} 1-\mathrm{C} 2$ facet joints. Position of the cages were confirmed by $\mathrm{C}$-arm image intensification, and three screws were used (one on $\mathrm{C} 1$ lateral mass and two on $\mathrm{C} 2$ vertebral body) to lock each cage (Fig. 1f, g and h). Use of this novel implant was approved by the local hospital ethics committee.

\section{Biomechanical evaluation \\ Specimen preparation}

Seven fresh frozen human cadaveric cervical spine specimens (kept at - 20 degrees in sealed bags) from subjects with no history of trauma or deformities involving the cervical spine were used (Fig. 2a). No specimen was osteoporotic as confirmed by densitometry. Soft tissue structures, including the ligaments, joint capsules, intervertebral discs were all intact on visual inspection. Before the test, specimens were thawed overnight at room temperature. Neutral alignment of the cervical spine was carefully maintained during preparation when both ends of the specimen were embedded with polymethylmethacrylate (PMMA) and mounted onto a spine motion simulator (MTS Corp, Eden Prairie, MN USA).

\section{Testing protocol}

Pilot markers were attached anteriorly to the $\mathrm{C} 1 \mathrm{right}$ lateral mass and the $\mathrm{C} 2$ vertebral body to track their respective segmental range of motion (ROM), which was measured and analyzed using NDI Optotrak Certus, a 3D movement measuring system (Norther Digital Inc., Ontario, Canada). Classic posterior $\mathrm{C} 1$ lateral mass-C2 pedicle screw (C1LM-C2PS) instrumentation [10] was first performed. Each specimen was pre-conditioned for three loading cycles with moment variation between 2 $\mathrm{Nm}$ and $-2 \mathrm{Nm}$ to minimize viscoelasticity effects. (The moment of $2 \mathrm{Nm}$ was chosen because based on the literature $[9,11]$, the most commonly used values in cervical spine studies range from $1.5 \mathrm{Nm}$ to $2.5 \mathrm{Nm}$.) Then, starting from a neutral position, each specimen was tested in three different directions of motion in the order of extension-flexion (i.e. anterior-posterior translation), lateral bending, and axial rotation, while keeping the displacement under control between angles corresponding to the moments between $2 \mathrm{NM}$ and $-2 \mathrm{NM}$ as determined in the previous viscoelasticity mitigation step (Fig. 2b, c). The posterior implants were then removed and two personalized 3DPLCs were inserted anteriorly between the C1-C2 facet joints (Fig. 2d, e, f, g) in each specimen. A second round of biomechanical evaluation was then performed. Segmental movement between C1 and $\mathrm{C} 2$ was measured for each direction of motion with either type of internal fixation and data were analyzed using paired sample T-test (SPSS, 17.0 statistics). The precision of the NDI system for rigid body displacement measurement is $0.01 \mathrm{~mm}$.

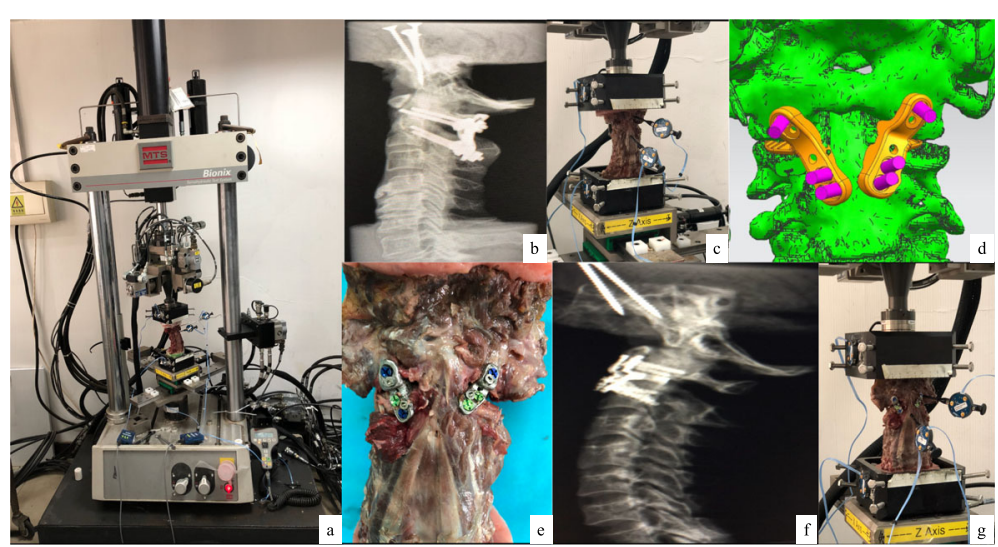

Fig. 2 a Overview of the specimen and the spine motion simulation system; $\mathbf{b}$ Lateral X-ray after posterior instrumentation; c Setup for biomechanical evaluation following posterior instrumentation; $\mathbf{d}$ Computer-aided design model of 3DPLC; e Specimen with 3DPLC inserted anteriorly; $\mathbf{f}$ Lateral X-ray after anterior instrumentation; $\mathbf{g}$ Setup for biomechanical evaluation following anterior instrumentation 


\section{Results}

\section{Clinical results}

Improvement of his neurological function was evident immediately after surgery. A Philadelphia collar was used for 3 months for outdoor activities. He was able to walk independently 1 month post-operatively. At the 12-month follow-up, CT scan (axial, sagittal, coronal) demonstrated properly-positioned 3DPLCs, evidence of osseo-integration at the bone-implant interface, and no subsidence or displacement of the 3DPLCs (Fig. 1i, j, k, and l). Eighteen months out of surgery, the mJOA score improved to 15 , and lateral X-ray confirmed reduction of atlanto-axial dislocation. Even though partial osseous collapse of $\mathrm{C} 1$ lateral masses was suspected, there was no implant subsidence or loosening of the screws (Fig. $1 \mathrm{~m}$ ).

\section{Biomechanical results}

Both the posterior and the anterior constructs provided strong fixation. In all three directions of motion, the amount of segmental movement was limited and there was no significant difference observed between the two types of fixation (Fig. 3, Table 1).

\section{Discussion}

We previously described the first utilization of 3Dprinted implants in spine surgery in 2016 for anterior C2 reconstruction following spondylectomy due to Ewing sarcoma in an adolescent [8]. Phan et al. [12] reported a posterior $3 \mathrm{D}$-printed implant for atlanto-axial arthrodesis in a 65-year female, however, she was followed up for only 2 months. Additional report on the use of 3D-printed constructs in the upper cervical spine was rare in the literature.
The purpose of the current study was to illustrate the first anterior customized implant (3DPLC) in the upper cervical spine for an IAAD patient with mid-term follow-up. Surgical treatment of IAAD consisted of two steps: release of the peri-odontoid soft tissue to allow anatomic reduction (typically trans-oral from the anterior) and strong fixation (typically from the posterior) to allow early fusion. 3DPLC was an anterior implant that could provide solid fixation (comparable to the strongest posterior construct in all forms of ROM) along with a cage that facilitated osseo-integration. Since trans-oral release often needed to be performed in patients with IAAD, any posterior instrumentation would require a second surgical procedure with associated morbidity, which could have been avoided if an anterior instrumentation and fusion procedure were to be performed following trans-oral release. Use of our novel implant following the trans-oral release procedure could help avoid both a second-stage posterior surgery and the need for iliac bone harvesting. Additionally, it could be used as a salvage technique in cases where abnormal anatomy or previous surgical procedures precluded the use of posterior instrumentation and anterior instrumentation became the only viable option.

Existing posterior constructs for atlantoaxial fixation included C1LM-C2PS, C1-C2 trans-articular screws (C1-C2 TA), C1 lateral mass and $\mathrm{C} 2$ trans-laminar screws (C1LM-C2TL), and C1-C2 lateral mass screws (C1-C2 LM). The biomechanical properties of these constructs had been assessed in previous studies [13-15]. A meta-analysis [13] of fifteen articles found that $\mathrm{C} 1-\mathrm{C} 2$ $\mathrm{LM}$ is less stable against axial rotation, C1LM-C2TL is less stable against lateral bending, while C1LM-C2PS represents the strongest form of atlantoaxial fixation. On
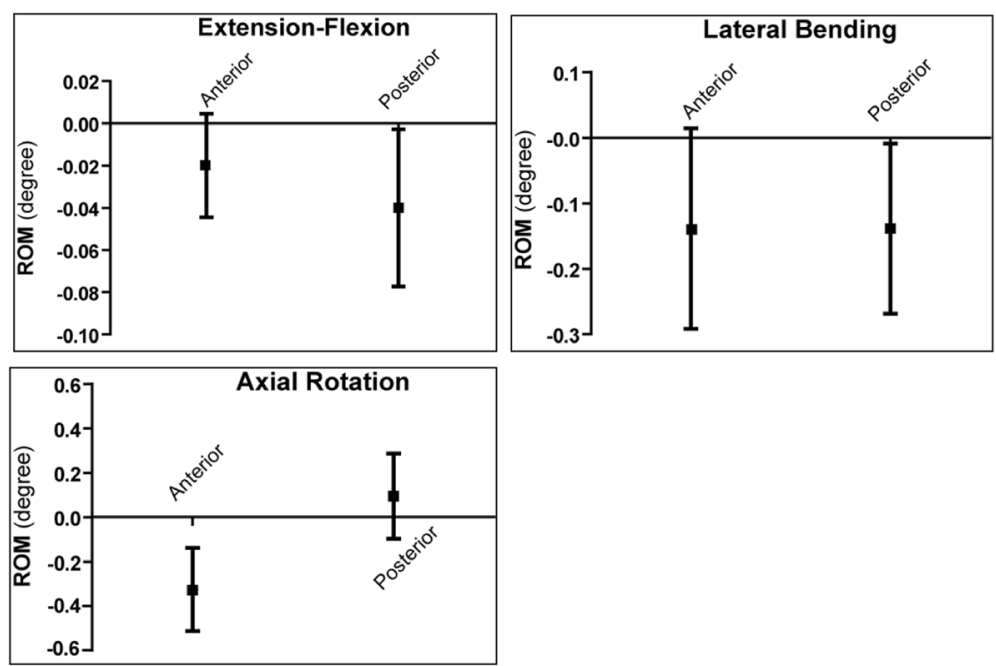

Fig. $\mathbf{3}$ In vitro biomechanical tests showed that segmental movement in all three directions was limited and there was no significant difference between the two types of fixation 
Table 1 Comparison between 3DPLC and the conventionl posterior construct in three modes of motion

\begin{tabular}{llll}
\hline Motion mode & ROM (degree) & & \\
\cline { 2 - 4 } & $\begin{array}{l}\text { Anterior Fixation } \\
\text { (Mean } \pm \text { SEM) }\end{array}$ & $\begin{array}{l}\text { Posterior Fixation } \\
\text { (Mean } \pm \text { SEM) }\end{array}$ & $P$ value \\
\hline Flexion \& Extension & $0.024 \pm 0.028$ & $-0.004 \pm 0.005$ & 0.33 \\
Lateral Bending & $-0.013 \pm 0.006$ & $0.017 \pm 0.015$ & 0.09 \\
Axial Rotation & $-0.007 \pm 0.003$ & $-0.173 \pm 0.167$ & 0.34 \\
\hline
\end{tabular}

the other hand, the primary form of anterior fixation in the atlantoaxial region in the literature was the anterior trans-oral atlantoaxial reduction plate (TARP). The TARP construct offered comparable stability to the C1LM-C2PS constructs in all directions of segmental movement except for flexion [16]. In comparison, results from the current study showed that 3DPLC could provide stability in all directions of movement equivalent to the conventional C1LM-C2PS construct (Fig. 3). Additionally, fixation of the new 3DPLC was easier than the TARP construct and its 3D-printed porous micro-structure could facilitate osseo-integration, such that graft harvest from the iliac crest, which could be fraught with complications (e.g. pain, wound dehiscence, etc.), became obsolete with this new implant. Lastly, the 3DPLC had a lower profile when compared to TARP, especially in the midline where the incision was made. Therefore, the 3DPLC might better facilitate wound healing in the posterior pharyngeal wall.

There were several limitations to this study. First, this was a case report with mid-term follow-up; second, the biomechanical evaluation did not include a fatigue test; and third, it currently took 2-3 weeks to manufacture the customized implant, prohibiting its use in emergency cases. However, developing anterior implants for atlantoaxial instrumentation and fusion was a project worthy of continuing efforts and could be built upon results from our current study.

\section{Conclusions}

The novel implant herein described represented a new option in the treatment of irreducible atlantoaxial dislocation that could provide strong anterior support for solid fixation and fusion with a low profile and a microstructure that obviated the need for bone grafting.

\section{Supplementary Information}

The online version contains supplementary material available at https:/doi. org/10.1186/s12891-021-03987-2.

Additional file 1.

\section{Abbreviations}

mJOA: modified Japanese Orthopaedic Association; ROM: range of motion; IAAD: irreducible atlantoaxial dislocation; CVJ: cranio-vertebral junction; 3DPLC: 3D-printed locking cage; AAD: atlantoaxial dislocation;
PMMA: polymethylmethacrylate; C1LM-C2PS: C1 lateral mass-C2 pedicle screw; C1-C2 TA: C1-C2 trans-articular screws; C1LM-C2TL: C1 lateral mass and C2 trans-laminar screws; C1-C2 LM: C1-C2 lateral mass screws;

TARP: trans-oral atlantoaxial reduction plate

\section{Acknowledgements}

Not Applicable.

\section{Authors' contributions}

SW and ZL designed the study; HL and YT performed the biomechanical test; SW and NX performed clinical follow up and drafted the manuscript; all authors agreed upon the publication of the manuscript.

\section{Funding}

This study was partially supported by Capital's Fund for Health Development and Research (2018-4-4097) for the performance of biomechanical test.

\section{Availability of data and materials}

Available upon reasonable request to the corresponding author.

\section{Ethics approval and consent to participate}

This study was approved by the Ethics Committee of Peking University Third Hospital and written consent to participate was obtained from the patient.

Consent for publication

Not Applicable.

Competing interests

None.

Received: 17 July 2020 Accepted: 19 January 2021

Published online: 29 January 2021

\section{References}

1. Wang $\mathrm{S}$, et al. Novel surgical classification and treatment strategy for atlantoaxial dislocations. Spine (Phila Pa 1976). 2013:38(21):E1348-56.

2. Wu $X$, et al. Surgical strategies for the treatment of os odontoideum with atlantoaxial dislocation. J Neurosurg Spine. 2018;28(2):131-9.

3. Guan J, et al. Effectiveness of posterior reduction and fixation in atlantoaxial dislocation: a retrospective cohort study of 135 patients with a treatment algorithm proposal. Eur Spine J. 2019.

4. Wang $\mathrm{S}$, et al. Atlantoaxial rotatory fixed dislocation: report on a series of 32 pediatric cases. Spine (Phila Pa 1976). 2016:41(12):E725-32.

5. Wang $\mathrm{C}$, et al. Open reduction of irreducible atlantoaxial dislocation by transoral anterior atlantoaxial release and posterior internal fixation. Spine (Phila Pa 1976). 2006;31(11):E306-13.

6. Yin QS, et al. Transoral atlantoaxial reduction plate fixation for irreducible atlantoaxial dislocation. Chin J Traumatol. 2006;9(1):14-20.

7. Cai H, et al. 3D Printing in Spine Surgery. Adv Exp Med Biol. 2018;1093: 345-59.

8. $\mathrm{Xu} \mathrm{N}$, et al. Reconstruction of the upper cervical spine using a personalized 3D-printed vertebral body in an adolescent with Ewing sarcoma. Spine (Phila Pa 1976). 2016;41(1):E50-4.

9. Tetreault $L$, et al. The modified Japanese Orthopaedic association scale: establishing criteria for mild, moderate and severe impairment in patients with degenerative cervical myelopathy. Eur Spine J. 2017;26(1):78-84.

10. Wang $\mathrm{S}$, et al. Radiographic evaluation of the technique for $\mathrm{C} 1$ lateral mass and C2 pedicle screw fixation in three hundred nineteen cases. Spine (Phila Pa 1976). 2011;36(1):3-8.

11. Yang J, et al. In vivo study of a self-stabilizing artificial vertebral body fabricated by electron beam melting. Spine (Phila Pa 1976). 2014;39(8): E486-92.

12. Phan $\mathrm{K}$, et al. Application of a 3D custom printed patient specific spinal implant for C1/2 arthrodesis. J Spine Surg. 2016;2(4):314-8.

13. Du JY, et al. Biomechanical analysis of screw constructs for atlantoaxial fixation in cadavers: a systematic review and meta-analysis. J Neurosurg Spine. 2015;22(2):151-61.

14. Chun DH, et al. Biomechanical comparison of four different Atlantoaxial posterior fixation constructs in adults: a finite element study. Spine (Phila Pa 1976). 2018;43(15):E891-7. 
15. Liu S, et al. Biomechanical evaluation of $\mathrm{C} 1$ lateral mass and $\mathrm{C} 2$ translaminar bicortical screws in atlantoaxial fixation: an in vitro human cadaveric study. Spine J. 2018;18(4):674-81.

16. Zhang B, et al. Biomechanical comparison of modified TARP technique versus modified Goel technique for the treatment of basilar invagination: a finite element analysis. Spine (Phila Pa 1976). 2016;41(8):E459-66.

\section{Publisher's Note}

Springer Nature remains neutral with regard to jurisdictional claims in published maps and institutional affiliations.

Ready to submit your research? Choose BMC and benefit from:

- fast, convenient online submission

- thorough peer review by experienced researchers in your field

- rapid publication on acceptance

- support for research data, including large and complex data types

- gold Open Access which fosters wider collaboration and increased citations

- maximum visibility for your research: over $100 \mathrm{M}$ website views per year

At BMC, research is always in progress.

Learn more biomedcentral.com/submissions 